\section{Breast-milk Jaundice}

When a newborn baby is jaundiced a knowledge of the time when the jaundice appeared and its subsequent course is helpful in diagnosis. If it is evident before 36 hours of age, it is likely to be due to haemolysis and must be taken very seriously. Jaundice appearing a little later, but reaching its peak during the first week and then fading rapidly, is usually "physiological," though other diagnoses such as systemic infection and some less common causes of haemolysis should be considered if the baby is unwell or the jaundice is marked. Jaundice which appears after the first week, or which persists after the age of 10 days in a full-term baby, is much less common. Its differential diagnosis includes neonatal hepatitis, chronic infections, biliary atresia, galactosaemia, hypothyroidism, and certain rare inborn errors of bilirubin metabolism such as Crigler-Najjar syndrome.

In 1963 a hitherto undescribed condition was added to this list ${ }^{12}$-namely, prolonged jaundice due to unconjugated hyperbilirubinaemia occurring in some breast-fed infants, and believed to be due to inhibition of bilirubin conjugation by a substance present in breast milk. ${ }^{2-5}$ The jaundice remitted rapidly on changing the baby to cow's milk, and it sometimes recurred, but to a lesser extent, if breast feeding was reintroduced. The milk of these infants' mothers inhibited conjugation of bilirubin in vitro. And the breast-fed, but not the bottle-fed, siblings of affected infants frequently had severe and prolonged jaundice. ${ }^{4}$

The inhibitory substance was at first thought to be $3 a, 20 \beta$ pregnanediol, ${ }^{2} 4$ and when this substance was fed to two newborn infants (but not to two older ones) moderate jaundice resulted. A. Ramos and colleagues ${ }^{6}$ could not confirm that milk with high inhibitory activity contained pregnanediol nor that infants fed with pregnanediol became jaundiced, and a recent paper by B. P. F. Adlard and G. H. Lathe ${ }^{7}$ casts further doubt on the suggested pathogenesis of breast-milk jaundice. They found that pregnanediol does not inhibit bilirubin conjugation in (adult) human liver slices or microsomes.

Another possible explanation is that these babies may have a relatively low intake of milk. A. J. Newman and S. Gross ${ }^{1}$ gave data on weight gain in seven of their infants, and in four the gain was distinctly inadequate. It is commonly held that a low intake of fluid tends to cause neonatal hyperbilirubinaemia and a higher intake to prevent it, though there is some conflict of evidence on this point. Some studies have shown

1 Newman, A. J., and Gross, S., Pediatrics, 1963, 32, 995.

2 Arias, I. M., Gartner, L. M., Seifter, S., and Furman, M., fournal of Clinical Investigation, 1964, 43, 2037.

3 Stiehm, E. R., and Ryan, J., American fournal of Diseases of Children, 1965, 109, 212 .

4 Gartner, L. M., and Arias, I. M., Fournal of Pediatrics, 1966, 68, 54.

${ }^{5}$ Arthur, L. J. H., Bevan, B. R., and Holton, J. B., Developmental Medicine and Child Neurology, 1966, 8, 279.

Ramos, A., Silverberg, M., and Stern, L., American Fournal of Diseases of Children, 1966, 111, 353.

Adlard, B. P. F., and Lathe, 'G. H., Archives of Disease in Childhood, $1970,45,186$.

${ }^{8}$ Laurance, B. M., and Smith, B. H., Lancet, 1962, 1, 589.

9 Smallpeice, V., and Davies, P. A., Lancet, 1964, 2, 1349.

10 Wharton, B. A and Bower, B. D., Lancet 1965, 2, 969.

11 Wennberg, R. P., Schwartz, R., and Sweet, A. Y., Fournal of Pediatrics, 1966, 68, 860.

12 Wu, P. Y. K., Teilmann, P. Pediatrics, 1967, 39, 733.

England fournal of Medicine, 1961, 265

Hubbell, J. P., jun., et al., New England fournal of Medicine, 1961, 265,

14 Haworth, J. C., and Ford, J. D., Archives of Disease in Childhood, 1963, $38,328$.

15 Beard, A. G., et al., Fournal of Pediatrics, 1966, 68, 329

${ }^{16}$ Cornblath, M., Forbes, A. E., Pildes, R. S., Luebben, G., and Greengard, J., Pediatrics, 1966, 38, 547.

17 Mamunes, P., Baden, M., Bass, J. W., and Nelson, J., Pediatrics, 1969 $43,241$.

18 Darling, J. A. B., and Harkness, R. A., Archives of Disease in Childhood, $1969,44,782$. that babies with a low birth weight ${ }^{8-12}$ and infants of diabetic mothers ${ }^{13}$ become less jaundiced if they are given a relatively liberal fluid intake from the start, but other workers have not found this effect. ${ }^{14-17}$ The rapid clearing of breast-milk jaundice when bottle feeding is started ${ }^{1345}$ might be accounted for at least in some cases simply by an increased fluid intake. (In none of the papers quoted has fluid intake before and after starting bottle feeding been compared.) However, this explanation would not account for L. M. Gartner and I. M. Arias's finding that the milk of mothers whose babies had breast-milk jaundice consistently showed far greater inhibition of conjugation in vitro than milk from mothers of unjaundiced infants. ${ }^{4}$ Whatever the reservations about the applicability of these in vitro results to the human infant ${ }^{7}$ this observation obviously requires an explanation. Breast-milk jaundice may be a more complex problem than was at first thought. ${ }^{18}$ Possibly some cases are due to so far unidentified inhibitors in milk and some to inadequate fluid intake.

Though neonatal jaundice from any cause may be dangerous if the serum bilirubin level exceeds $20 \mathrm{mg}$. per $100 \mathrm{ml}$., it seems to be generally agreed that breast-milk jaundice is relatively harmless and will gradually fade, so there is no need to stop breast feeding if the mother wishes to continue with it. $^{345}$ But when this diagnosis is suspected the clinician would probably do well to check that the baby's weight gain suggests an adequate intake of milk.

\section{M.R.C. and the Universities}

The relationship between the Medical Research Council and the universities is both intimate and delicate, requiring some tact on both sides if it is to prosper. Financing as it does many investigations carried out in universities, the M.R.C. is, if not a rich, at least a fairly affluent uncle to academic staffs. Its funds are welcome and its good judgement in allocating them acknowledged. But in drawing into research many of the brightest sparks of their generation it does also to a certain extent remove them from the opportunity of teaching. And though in public declarations the twin virtues of research and education are invariably firmly linked, presented as mutually enhancing, and accepted as the dual responsibility of academic staffs, to the individuals undertaking them they more often seem to pull in opposite directions.

It is worth noting, therefore, that the M.R.C. reiterates in its latest annual report ${ }^{1}$ that it seeks to complement and not to rival research in the universities or the National Health Service. And it emphasizes that "the closest possible liaison and co-operation between the Council and the universities are thus imperative." For some years before, and for the 50 years since, it was granted its royal charter in 1920, the M.R.C. has been notably successful in fostering research, much of it through the universities, so that its record bears witness to the happy relationship it has established with them. Through short- and long-term grants it has enabled many individual members of academic staffs to survive the financial crises to which research is especially prone, and its separate research units-whose members have collected a surprising number of

\footnotetext{
${ }^{1}$ Medical Research Council, Annual Report April 1969-March 1970. London,
} H.M.S.O. 1970. 
Nobel prizes-have dovetailed neatly into the universities of which they are often a part.

Observing that medical research is largely conducted by or within universities, the annual report is doing no more than note one unexceptionable reason why the M.R.C.'s links must always be of the closest with those institutions. But the clinician is aware too of the enormous benefits to the treatment of patients that the pharmaceutical industry has brought about in the last 20 years. The medicinal revolution, unfashionable though it is to say so in some circles, owes much of its success to the discovery, isolation, or purification of drugs and other remedies through research undertaken in drug firms. Though the molecular roulette for quick profit has often been criticized, the barely mentionable though not unknown practice of facile but pointless investigation for quick prestige in academic circles usually gets by. In this field of judgement - the choice of worthwhile research-the M.R.C. has exerted a thoroughly healthy influence and been conspicuously successful. Selecting the right projects and backing these financially must always be a bit of a gamble, but the Council takes care to shorten the odds against it by having as its members and advisers many leaders in their field, most of them in university appointments.

At present the M.R.C. is giving priority in its support to four special problems of our time. They are mental disorder, arterial disorder (in particular coronary thrombosis), population control, and drug dependence (including tobacco smoking). It considers also that certain specialties need encouragement "if research is to be developed"-namely, psychiatry, clinical neurology, obstetrics and gynaecology, dermatology, dentistry, virology, and mycology. Anyone with enthusiasm for his subject could make out a good case for having it added to the list, so many are the promising lines of research that seem to lie open in medicine today, but one useful addition might be resuscitation and the treatment of injuries, for accidents and attempted suicide now constitute a substantial proportion of hospital work.

The latest report departs from custom in that it omits the bulky section giving details of the research supported by the M.R.C. That is to be published as a separate handbook.

\section{Handicapped Children}

The face of our social services has undergone increasing scrutiny in recent years: and the more it has been scrutinized the more warts and other blemishes are discovered-the iniquities of Ely, ${ }^{1}$ the accusations of Sans Everything, ${ }^{2}$ and the revelations of Put Away. ${ }^{3}$

Now comes Living with Handicap, ${ }^{4}$ a report published by the National Bureau for Co-operation in Child Care. It is based on data compiled by a multidisciplinary working party. Fifty-eight professional and voluntary organizations and some individuals submitted written evidence; ten county and county borough councils gave accounts of their respective facilities.

1 Committee of Enquiry into Allegations of Ill-treatment of Patients and other Irregularities at the Ely Hospital, Cardiff, Report, Cmnd. 3975. London, H.M.S.O., 1969.

2 Robb, B., Sans Everything: A Case to Answer. London, Nelson, 1967.

3 Morris, P., Put Away: A Sociological Study of Institutions for the Mentally Retarded. London, Routledge and Kegan Paul, 1969.

4 Living with Handicap, ed. E. Younghusband, D. Birchall, R. Davie, M. L. Kellmer Pringle. National Bureau for Cooperation in Child Care, Adam House, 1 Fitzroy Square, London W'.1., 50s. 1970.

5 Committee on Local Authority and Allied Personal Services, Report, Cmnd. 3703. London, H.M.S.O., 1968.
Finally, an indication of "consumer reactions" was obtained from letters written by 412 parents in response to invitations in the national press. This is obviously a biased sample and represents the views of the more articulate, intelligent, and socially conscious section of the community. Nevertheless, despite their statistical invalidity the replies are poignant, and extracts from them serve as texts on which each chapter of the report is based. One father wrote that there was "more autism among the local authorities than he had ever found in his daughter." This sad comment is echoed in many other letters and highlights the feeling of hopelessness engendered by the rigid departmentalization of the available services, with the inevitable buck-passing. Such despair reinforces the recommendation in the Seebohm report, ${ }^{5}$ wholeheartedly endorsed by the working party, that social and family needs can be effectively met only through a compact social services department.

The report is concerned with the problems and indeed agonies of parents and families trying to cope with handicapped children. The range of handicaps is enormous. Physically they may vary from the cosmetic disadvantages of congenital malformations of the external ear to those tragic, living monuments to man's pharmacological conceit, the thalidomide children. They include varieties of sensory deprivation from partial to complete. There are the degrees of intellectual impairment; and last but by no means least there is the full range of psychological troubles, from emotional disturbances, through behaviour disorders, to autism and childhood psychosis. For good measure throw in the permutations and combinations of multiple handicaps and the problems, individually and collectively, stretch out to infinity.

The report makes it clear that mental handicap is far less easily tolerated by the public at large than physical handicap. As a sort of corollary, the worst fear of parents of mentally handicapped children seems to be that, for whatever reason, they will finally be admitted to a subnormality hospital. Such is the reputation of these institutions, not entirely deserved, but the result no doubt of the indiscriminate mud-slinging to which they have been lately subjected.

Any assessment of the size of the need to be met in numerical terms is bound to fall wide of the mark for the simple reason that one of Parkinson's laws applies: the provision of any kind of special facility will immediately uncover more children needing it than was originally estimated. None-the-less Michael Power and Jean Packman's approximation is quoted. They calculated that in 1966 there were 21,000 children with physical handicaps and 24,000 with mental handicaps living in boarding schools and hospitals, plus a further 115,600 children who were receiving help from their homes-a gigantic total.

The ultimate plea of the working party is that each child should receive help, including formal education, according to his individual needs, and that this should be given with the minimum of separation from his normal fellows and the minimum disturbance of normal family life. It would be churlish to maintain that nothing is being done to this end. In truth, a great deal is achieved by both professional and voluntary organizations; but the ideal of a tailor-made service to suit each handicapped child will always be unrealistic. As living standards rise, however, so should the quality of care provided for the handicapped. The new Secretary of State must soon decide what his priorities are to be-and he has already shown sympathy for the mentally handicapped (see Parliament, p. 232). This report makes a powerful additional claim for all children who need any form of special care. 